\title{
Vibration Characteristic of the Bolter Arm under Heavy Load
}

\author{
Zhiru Yang ${ }^{*}$, Nan Zheng and Dezheng Le \\ School of Mechanical Engineering, Jiangsu University, Zhenjiang 212013, China \\ *Corresponding author e-mail: wan_009@126.com
}

\begin{abstract}
When the anchor rig is working, the anchor arm is in a heavy-duty working environment and is more susceptible to damage. The effects of bolter arm on the jumbolter stability are studied. According to the mechanical structure of the bolter arm, a vibration model is established, and the model is imported into Simulink for simulation. The frequency response of each step of the jumbolter is obtained. The correctness of the vibration model is verified by comparison with the theoretical value. Then, the vibration responses of the jumbolter center of gravity in $X / Y / Z$ directions are simulated, and the stability of bolter arm in the working process is studied.
\end{abstract}

KEYWORDS: vibration characteristic, bolter arm, jumbolter, heavy load

\section{Introduction}

The bolter arm on jumbolter is the machine that a jumbolter is attached to a bolt drilling equipment which provides the jumbolter with the drilling function [1, 2]. Bolter arm is the jumbolter moving parts, jumbolter design. The bolter arm work jumbolter must be stability, and bolter arm on the jumbolter impacts its dynamic performance [3]. The influence of bolter is an important index to evaluate whether bolter arm can be successfully applied in actual working conditions [4, 5].

For a simple vibration system, its natural frequency represents the inherent characteristics of the system; for complex systems, its inherent characteristics include the natural frequency of each order mode, mode shape and damping and so on [6-8]. The purpose of calculating and determining the inherent characteristics of the system is to prevent the system from resonating during operation and to lay the foundation for further kinetic analysis of the system [9-10]. Most practical mechanical systems and plant structures are continuous, non-uniform elastomers that, for ease of analysis, are approximated as a system of finite degrees of freedom to meet the accuracy requirements and are discretized into a system of multiple degrees of freedom. 
Bolter arm drilling resistance support the role of resistance to reverse the cutting arm, and the cutting arm is mounted on the jumbolter arm body. The bolter arm is bound to cause the jumbolter vibration, so bolter arm and jumbolter should be taken as a whole system to study bolter arm work machine dynamic characteristics.

\section{Vibration model setup}

As is shown in Figure 1, bolter arm mainly consists of 6 parts: body, beam, support A / B / C, motor. First of all, the virtual experimental model of whole machine characteristics under bolter arm working condition must be established. Before building the jumbolter dynamics model, we first make the following assumptions:

(1) Uniaxial compressive strength of coal wall is constant;

(2) Jumbolter and bolter arm has uniform mass distribution and small flexibility;

(3) Both the jumbolter and the bolter arm are operating normally, without causing jumbolter vibration.

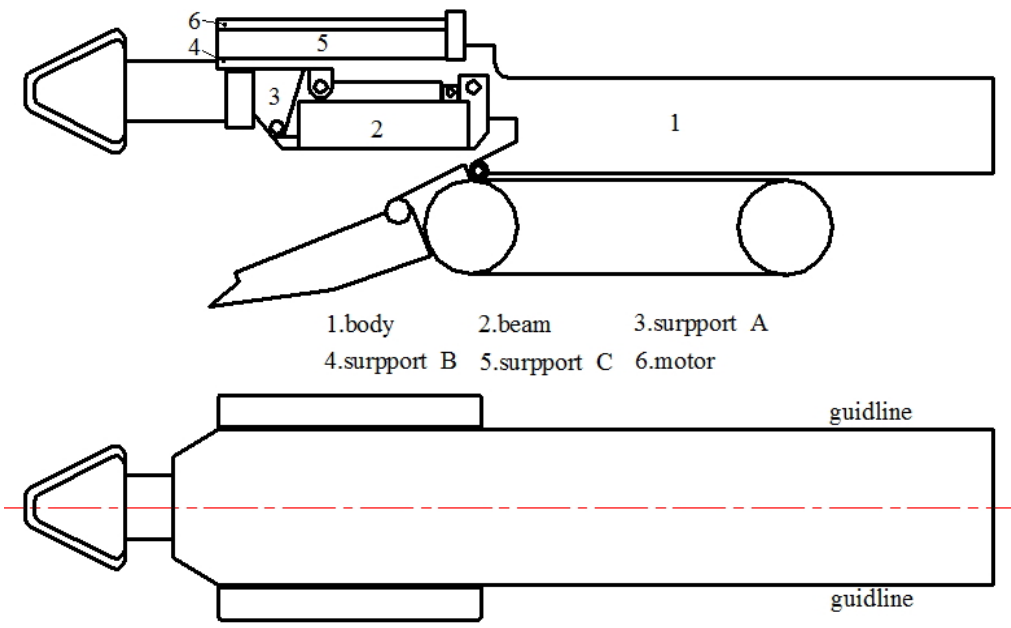

Figure 1 Bolter arm structure.

The jumbolter crawler, shovelboard, the mainframe, a movement, after the support and so on are taken as a whole component. Also the bolter arm fixed slide and cutting are taken as a whole, and the bolter arm of the drill pipe, drill and rig Motor are taken as a whole for analysis. Bolter arm in the tunnel roof hole, the machine will have a certain longitudinal vibration analysis bolter arm work, which size of the machine vibration to determine bolter arm on the stability of the machine. The longitudinal vibration model of the whole machine shown in Figure 2. Bolter arm playing side holes when the whole machine vibration model and the 
establishment of longitudinal vibration model principle is basically the same, according to the theoretical formula to get the model time-domain response.

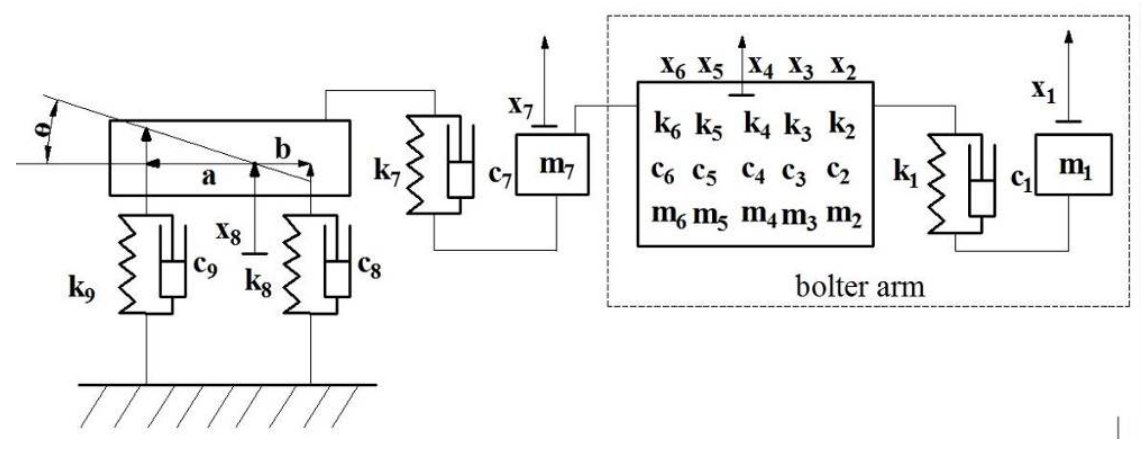

Figure 2 The longitudinal vibration model of jumbolter.

In order to dynamically display the time domain characteristics of the center of gravity of the whole machine, a simulation test of vibration excitation is carried out. The simulation excitation test system consists of four parts: exciter, input channel, output channel and jumbolter vibration model (Figure 2). The exciter is used as signal source for excitation test. The input channel is used to define the vibration input point and Direction, the output channel is used to measure the vibration response. According to the jumbolter virtual model established in Figure 2, the vibration simulation experiment is carried out. The stiffness and damping shown in Table 1 are added to the joints in the model. The parameters of the joint such as restraint and mass in the model are unchanged. The signal of the device also uses the load applied by the drill bit in the original model. After modification of the model, the Eigenvalue solver in RecurDyn is used to solve the problem so as to obtain the vibration frequency of the system and time domain information of corresponding points.

Table 1 Experimental data of sensor measurement accuracy

\begin{tabular}{ccccccccc}
\hline items & $\mathrm{i}=1$ & $\mathrm{i}=2$ & $\mathrm{i}=3$ & $\mathrm{i}=4$ & $\mathrm{i}=5$ & $\mathrm{i}=6$ & $\mathrm{i}=7$ & $\mathrm{i}=8$ \\
\hline $\boldsymbol{m}_{\mathbf{i}}(\mathrm{kg})$ & 40 & 450 & 200 & 200 & 450 & 10200 & 1800 & 30000 \\
\hline $\boldsymbol{k}_{\mathbf{i}}\left(\mathrm{kg} \cdot \mathrm{m}^{-1}\right)$ & 5 & 5 & 6 & 6 & 8 & 12 & 8 & 20 \\
\hline $\boldsymbol{c}_{\mathbf{i}}\left(\mathrm{N} \cdot \mathrm{s} \cdot \mathrm{m}^{-1}\right)$ & 10 & 10 & 12 & 15 & 15 & 20 & 40 & 45 \\
\hline
\end{tabular}

Notes: $\boldsymbol{m}_{\mathbf{i}}$-- quality; $\boldsymbol{k}_{\mathbf{i}}$-- elastic constants; $\boldsymbol{c}_{\mathbf{i}}$-- viscous constants.

\section{Results and discussion}

The theoretical value of each natural frequency is obtained by Matlab and compared with the natural frequency of the jumbolter virtual prototype (Figure 3). It

Published by Francis Academic Press, UK

$-58-$ 
can be seen from the comparison results that the difference between the 7th and 8th modes of the two models is $1 \mathrm{~Hz}$, The rest of the state calculation of the calculated frequency difference is not big, and because bolter arm operating frequency is lowfrequency range, so the use of virtual prototype simulation experiments, the results can be trusted.

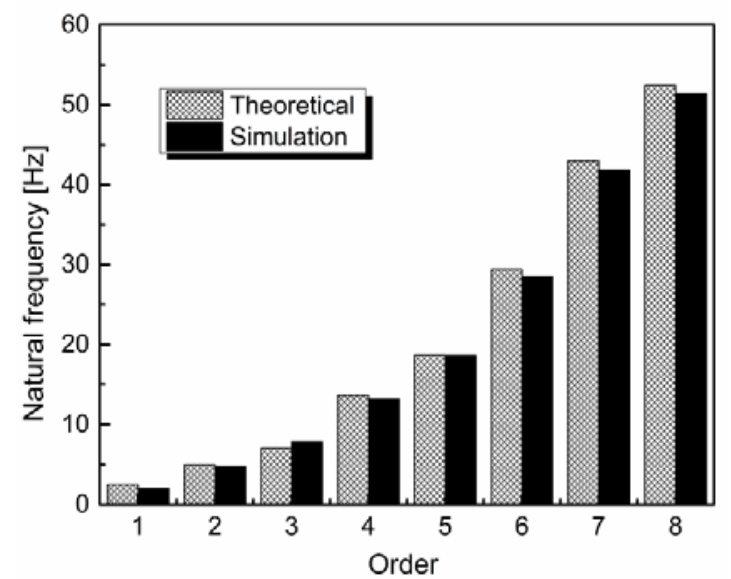

Figure 3 Bolter with jumbolter machine vibration frequency.

In order to analyze the vibration response of the jumbolter body, the displacement of the center of gravity of the machine in the three directions of $x, y$ and $\mathrm{z}$ was measured. The head-bolter the forward direction is the $\mathrm{x}$-axis direction, the vertical upward direction to the ground is the $y$-direction, and the jumbolter is the left-right swing direction is the z-direction.

The error at different times is shown in Figure 4 (a). From 0 to $50 \mathrm{~s}$, the displacement changes very little, starting from $50 \mathrm{~s}$, the displacement begins to show an error. Analysis reasons: boring machine turntable in the process of rotation, because of its slow rotation, acceleration, deceleration process is relatively stable, it caused a small deformation of the drill pipe, when the flip hydraulic cylinder, it completed within 20 s 90 Degree of the flip movement, the hydraulic cylinder start, braking faster, coupled with the drill pipe length $(1500 \mathrm{~mm})$, it caused the drill rod has been deformed, resulting in drill bit movement error; from $80 \mathrm{~s}$, the bit The error shows a nonlinear variation, which shows that the drill bit is offset by the load of the drill bit at work, and the error of the drill bit is nonlinearly superimposed with the advancement of the drill rod and the flexible deformation of the drill rod. Under actual conditions, the actual error of the drill bit is smaller than the simulation result due to the binding of the inner wall of the drill hole to the drill bit. However, the simulation result generally reflects the error development process of the drill bit. 


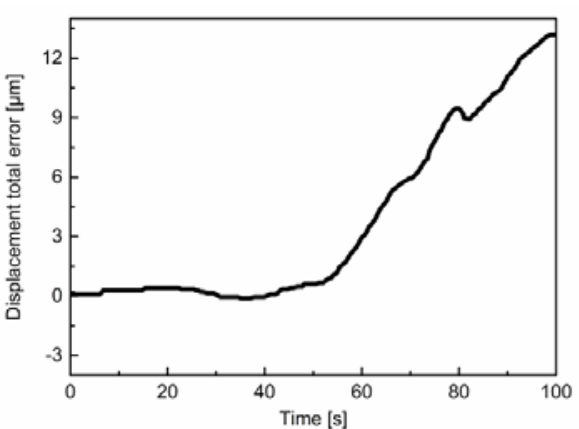

(a) Bolter head displacement error

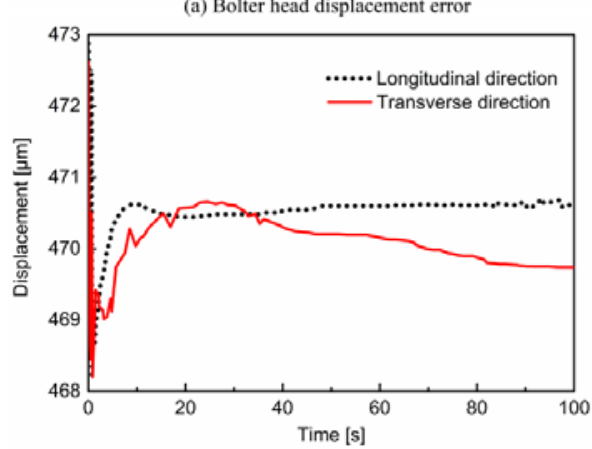

(c) Header-Bolter displacement in $\mathrm{Y}$ direction

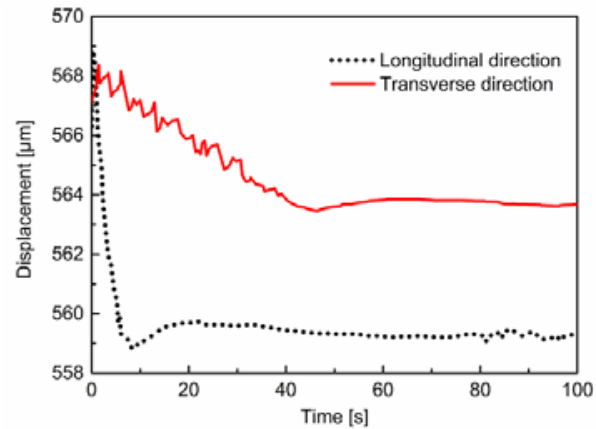

(b) Header-Bolter displacement in $\mathrm{X}$ direction

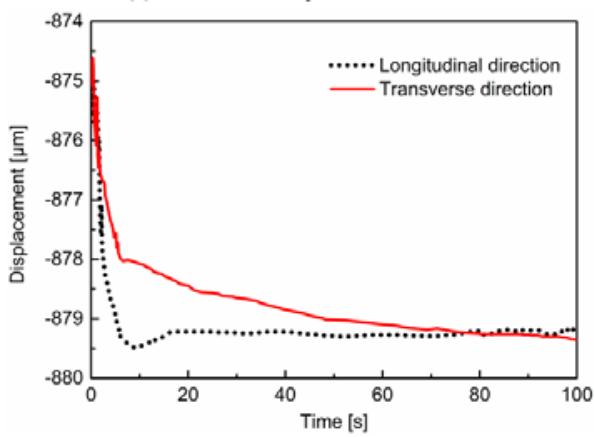

(d) Header-Bolter displacement in $\mathrm{Z}$ direction

Figure 4 The vibration time-domain response of machine gravity.

It can be seen from the time-domain curve of the center of gravity of the jumbolter in Figure 4 (b) - 5 (d) that in the $\mathrm{X}$ direction, the center of gravity displacement within $0 \sim 10 \mathrm{~s}$ is rapidly decreased by $4.8 \mathrm{~mm}$ and within $10 \sim 80 \mathrm{~s}$, The center of gravity displacement changes slowly, the variation is about $0.5 \mathrm{~mm}$, the center of gravity displacement changes with the amplitude of the excitation signal within $10 \sim 100 \mathrm{~s}$, but the variation is small, about $0.5 \mathrm{~mm}$; in the $\mathrm{Y}$ direction, The center of gravity of the main changes in the range of $0 \sim 20 \mathrm{~s}$ time, the rest of the time in a slowly changing state of gravity, the amount of change of about $0.5 \mathrm{~mm}$; in the $\mathrm{Z}$ direction, the center of gravity changes in the same direction with the $\mathrm{X}, \mathrm{Y}$; Direction of the center of gravity position curve shows: jumbolter machine in the start-up phase, that bolter arm position initial adjustment phase $(0 \sim 10 \mathrm{~s})$, due to the impact of the start-up inertia of the machine, the center of gravity will occur greater displacement, bolter arm Into the working state, the center of gravity displacement change is small, about $0.5 \mathrm{~mm}$, bolter arm hit the top of the roadway, the stability of the machine has almost no effect. bolter arm in the side of the hole, the center of gravity displacement changes and the top hole when the vibration situation is very similar, the difference is that when playing side holes, the whole center of gravity in the $\mathrm{Z}$ direction slightly larger $(0.8 \mathrm{~mm})$ around Simulation experiments show bolter arm playing side holes, the stability of the machine can be neglected. 
Academic Journal of Engineering and Technology Science

ISSN 2616-5767 Vol. 1, Issue 1: 56-62, DOI: 10.25236/AJETS.020007

\section{Conclusion}

Based on the analysis results, the following conclusions are drawn:

(1) The time-domain vibration characteristics of the center of gravity of the machine are studied by establishing the vibration model of the jumbolter when the top and side holes of the bolter arm are struck by the bolter arm. The research shows that when the top and side holes are hitting, Center of gravity of the vibration displacement are within $0.5 \mathrm{~mm}$, which shows bolter arm machine work is very smooth operation.

(2) The time-domain vibration characteristics of the whole machine were studied by setting up the jumbolter left-right swinging and up-down swinging cutting work, the vibration model of the whole machine. The research shows that the head-bolter vibration deviation caused by bolter arm Control within $2 \mathrm{~mm}$, indicating bolter arm on jumbolter cutting performance is very small.

\section{Acknowledgments}

This work was financially supported by the National Natural Science Foundation of China via grant number 51505194, the Natural Science Foundation of Jiangsu Province via grant number BK20150517 and the Senior Talent Start-up Foundation of Jiangsu University via grant number 15JDG033.

\section{References}

[1] H. Huang, Y. Sun, Y. Xue, and F. Wang (2017). Inspection equipment study for subway tunnel defects by grey-scale image processing, Advanced Engineering Informatics, vol.32, p.188-201.

[2] A. K. Mishra (2011). Conventional tunneling techniques using drill and blast New developments, Journal of Mines, Metals and Fuels, vol.59, p.212-218.

[3] A. K. Mishra, A. Sen, and D. Sain (2013). Innovative developments in drilling and blasting techniques for rapid excavation of drives in mines, Journal of Mines, Metals and Fuels, vol.61, p.194-201.

[4] M. Han, Z. Cai, and C. Qu (2014). Study on the critical driving speed of the tunnel boring machine cutterhead based on the dynamic stability. Chinese Journal of Mechanical Engineering, vol.50, p.10-16.

[5] M. Ramulu, T. G. Sitharam, A. K. Raina, P. B. Choudhury, and A. K. (2009). Chakraborty, Effect of repeated blast vibrations on damage intensity of granitic rock mass at an hydroelectric construction project, Journal of Mines, Metals and Fuels, vol. 57, p.148-155.

[6] Y. Zhang, B. Zhao, Y. Wang, and F. Chen (2017). Effect of machining parameters on the stability of separated and unseparated ultrasonic vibration of feed direction assisted milling, Journal of Mechanical Science and Technology, vol.31, p.851-858. 
[7] S. Toumi, L. Beji, R. Mlayeh, and A. Abichou (2017). Stabilization of torsional vibration in oil well drilling system, European Journal of Control, vol.35, p.1927.

[8] Y. Hou, M. Du, P. Fang, and L. Zhang (2017). Synchronization and stability of an elastically coupled tri-rotor vibration system, Journal of Theoretical and Applied Mechanics, vol.55, p.227-240.

[9] Kris K, Imme E, William (2004). Locally linearized dynamic analysis of parallel manipulators and application of input shaping to reduce vibrations, Journal of Mechanical Design, vol.126, p.156-168.

[10] K. Goshtasbi, M. Monjezi, and P. Tourgoli (2009). Evaluation of boring machine performance with special reference to geomechanical characteristics, International Journal of Mineral Processing, vol.16, p.665-670. 